\title{
An overview on ligands of therapeutically interest
}

\begin{abstract}
The principles governing metal-ligand complex stability and specificity depend on the properties of both the metal and the chelating agent. The exploration of coordination chemistry offers the real prospects of providing new understanding of intractable diseases and of devising novel therapeutics and diagnosis agents. Refinement in the approach to chelator design has come with a more subtle understanding of binding kinetics, catalytic mechanisms and donor interactions. Ligands that effectively bind metal ions and also include specific features to enhance targeting, reporting, and overall efficacy are driving innovation in areas of disease, diagnosis and therapy. In this contribution the topics of bioinorganic medicinal chemistry, chelating agents in the treatment of metallic ion overload in the body, and expanding the notion of chelating agent in medicine are successively dealt with, paying then attention to platinum, gold, iron, copper and aluminium ion metal complexes having medicinal interest. A tabular summary containing selected applications of ligands and complexes of therapeutic interest is also shown to including the most relevant and current bibliography. A number of papers concerning miscellaneous topics based on selected key words are also tabulated. Metal chelation principles offer wide new opportunities in the drug design field in addition to the classical answer of metal sequestration or elimination.
\end{abstract}

Keywords: ligands, complexes, therapeutic applications, new drugs

Volume 6 Issue 3 - 2018

\author{
Julia Martín,' Miguel Ropero Alés, ${ }^{2}$ Agustin G \\ Asuero $^{2}$ \\ 'Department of Analytical Chemistry, Escuela Politécnica \\ Superior, University of Seville, Spain \\ ${ }^{2}$ Department of Analytical Chemistry, Faculty of Pharmacy, \\ University of Seville, Spain
}

Correspondence: Julia Martín, Department of Analytical Chemistry, Escuela Politécnica Superior, University of Seville. C/ Virgen de África, 7, E-4I0I I Seville, Spain,Tel +34-9-5455-6250, Email jbueno@us.es

Received: March 26, 2018 | Published: May 302018

\section{Introduction}

The principles governing metal-ligand complex stability and specificity depend on the properties of both the metal and the chelating agent. ${ }^{1-4}$ Research in the field of inorganic medicinal chemistry has increased in the last two decades. In order to modify and control the features of metal ions in biological systems, a number of chelating ligand agents have been exploited. ${ }^{3,5}$ Metal ions show a vital function in the advance and pathology of a variety of ilness situations ${ }^{6-8}$ and, in some cases, are implicated in redox chemistry leading to oxidative stress. Many disorders implie a high level of metal ions in given tissues or body cell compartments. Solution to those generated problems are challenging requiring the therapeutic answers among posible mediations the use of new chelator agents. ${ }^{9-11}$

The wide success of platinum drugs has been promoting the development of both alternative platinum- and other non-platinum based compounds. ${ }^{12}$ The pharmaceutical industry has yet to appreciate the impact coordination chemistry can have on the design of new medicines. This may change in the future as skilled multidisciplinary practitioners develop their research using strategic approach to complex design. Refinement in the approach to chelator design has come with a more subtle understanding of biding kinetics, catalytic mechanisms and donor interactions. ${ }^{4,8,13}$ Rational ligand design offer to the medicinal chemistry, control over kinetic properties, such as the rate of ligand exchange. Our discussion is only a partial sample of the state of the art. Platinum, gold, iron, copper and aluminium complexes are mainly considered in this context. Summaries of papers related with either chelator agents (ligands) and their complexes or selected topics of therapeutic interest are shown in tabular form.

Metal chelation principles offer wide new opportunities in the drug design field in addition to the classical answers of metal sequestration or elimination. ${ }^{14-18}$ Ascertain the suitable chemical properties for a given application in ligand design is a hot topic. Synthesizing the appropriate coordination compound, for example, may modify a number of properties including charge, lipophilicity, lability, shape and redox potential. Custom agent chelators are thus at our disposal for testing cellular assays. Finding out whether and how those design elements are translated from the cellular content into the clinical practice is a challenge.

\section{Bioinorganic medicinal chemistry}

Chelates, among other applications, are used in medicine:5,7,19,20

a. To complex toxic metals.

b. To release traces of essential metals or deprive the cellular components of them.

c. To produce therapeutic interactions with cellular macromolecules.

For example, the most common method of treating heavy metal poisoning is to administer a chelating agent to remove the metal ion. Metal ions such as $\mathrm{As}, \mathrm{Hg}, \mathrm{Pb}, \mathrm{Au}$, form chelates with the thiol groups of enzymes and proteins blocking their functions. ${ }^{21,22}$ The effect of masses exerted by the chelating agent releases the enzyme from the metal ion, allowing its normal functioning, concentrating the metal chelate in the kidney for urinary excretion. The solubilizing chelating agents of the unithiol or penicillamine type (Figure 1) are the most effective.

Contrary to what happens with toxic organic substances, organisms are rarely capable of converting toxic metals into harmless derivatives. Hence, it relies heavily on therapeutic chelating agents to remove toxic metals. On the other hand, the chelate can act as a carrier to release a bioactive ligand. For example, the trans-[ $\mathrm{PtCl}_{3}(6-$ mp) 2]2- (Figure 1) transports the cytotoxic ligand 6-mercaptopurine through the membranes thus exhibiting its antitumor activity against cancer.

The fact that only the 8-hydroxy (oxine) member of the series (Figure 1), among the seven isomeric hydroxyquinoline is antibacterial, suggests ${ }^{20}$ that metal chelation must be involved in its action. In fact, oxine has been used for a long time in the analysis of metals due to its chelating capacity. But is it the antibacterial oxine because it sequesters essential metal ions for the bacterial cell, or is the chelate formed the toxic agent? Apparently, the chelate 1:1 ironoxine (or the chelate 1:1 copper-oxine for anti-fungal action) is the 
bactericide, since both oxine and Fe (II) alone kill staphylococci; neither is the iron-oxine chelate 1:2 the active agent. Other chelating agents, such as pyrithione and dimethyldithiocarbamic acid ${ }^{23}$ have a unique bioactivity (Figure 1) ${ }^{20}$ Possibly, metal chelates oxidize lipoic acid, the essential coenzyme for the decarboxylation of pyruvic acid.

Inorganic elements embrace those that exert a natural (either beneficial or harmful) biological effect, and other used with medicinal purposes as drugs or probes. ${ }^{18}$ Elements widely used such as iron, copper and zinc, are included as beneficial members of the first group, as well as others, e.g. cadmium and tungsten, used for only a few species. Nature ${ }^{24}$ has selected through evolution those elements:

a. Whose chemical use is facilitated.

b. Those that are sufficiently enough and bioavailable being thus their exploitation a benefit for the organism.

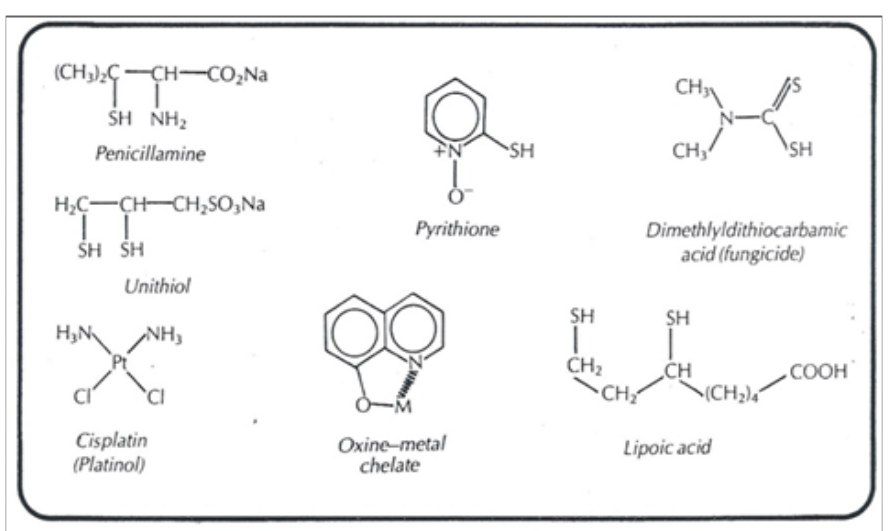

Figure I Chemical structure of some ligands of therapeutic interest. ${ }^{20}$

Most of the metal cations present in biological systems exist as chelates or coordination complexes, and monitoring the interaction of these metals with cellular components is a complex task. ${ }^{18}$ For example, calcium plays a role in enamel and toothpaste, iron in blood and muscle function, molybdenum in the metabolism of purine, zinc in insulin and in various enzymatic systems, chromium in the metabolism of glucose, and magnesium in the transmission of nerve impulses. ${ }^{20}$ In Figure 2 the periodic biomedical table is observed, figuring the elements with different colours associated with its class or function. ${ }^{25}$

The practice of medicinal inorganic chemistry goes back to 5000 years ago. ${ }^{26-29}$ The use of copper for the sterilization of water by the Egyptians dates back to 3000 years ago. The Arabian and Chinese used gold in varying medicines 3500 years ago (more because of its prized nature than for its proper medicinal action). The discovery of zinc as a promoter of wound healing occurred about 1500 years ago, a time when various iron-based remedies were already applied in ancient Egypt.

The biomedical inorganic chemistry (Table 1) ${ }^{30}$ (Figure 3$)^{19,31}$ is a new important area of chemistry and offers potential for the design of new therapeutic and diagnostic agents, ${ }^{8,15,32,33}$ and therefore, for the handling and the understanding of disorders that lack treatment. Metal ions, including metalloenzymes, activate or biotransform a pleyade of organic compounds used in medicinal practice, that as such compounds do not exert such an action. Organic compounds may also have an effect, either direct or indirect, on the metabolism of the metal ion. ${ }^{30}$

The functions of metal ions ${ }^{27,31,35}$ in biology are shown in Table $2,{ }^{30}$ and their importance is shown in Table $3 .^{30}$ Medicinal chemistry ${ }^{36}$ allows exploiting a wide range of reactivities based on the different coordination number and geometries available, ${ }^{28}$ the varying oxidation states, the thermodynamics and kinetics features, Table $4,,^{30}$ and the inherent properties of the metal cations and the individual ligands.

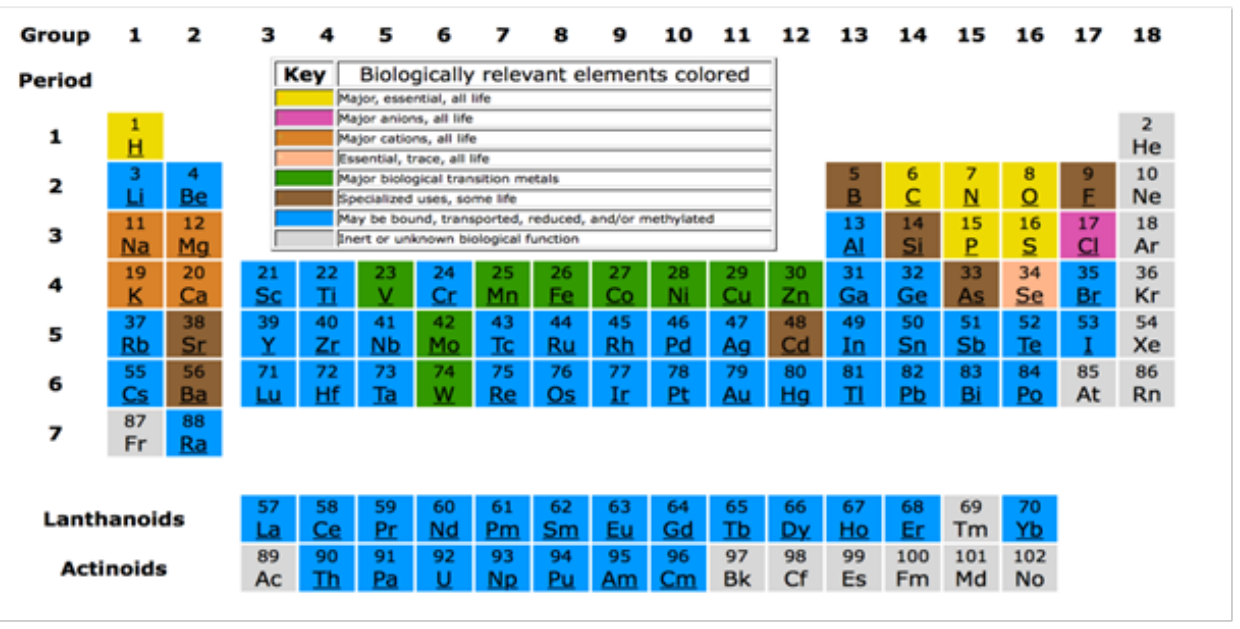

Figure 2 The biochemical periodic table..$^{25}$

Advantage can also be taken of the properties of biologically exotic elements, e.g., the transition elements of the first and second row, and the lanthanides. Gadolinium, a dark lanthanide element, is located in the middle of the Periodic Table. Due to their (unique) characteristics magnetic properties, gadolinium has come to occupy a place in medical diagnosis in the course of a couple of decades.
Gadolinium (III) is at the centre of MRI (magnetic resonance image), one of the spectacular advances in medicine, ${ }^{37}$ in a similar way to platinum in cancer therapy, or technetium in cardiac scanning. A special issue of Accounts of Chemical Research containing reviews on molecular image chemistry was published in 2009. 
Table I Topics to be covered by biomedical inorganic chemistry ${ }^{30}$

\begin{tabular}{|c|c|c|}
\hline No & Issue & Content \\
\hline \multirow[t]{2}{*}{ I } & The Biomedical Periodic Table & Essential elements \\
\hline & & Anticancer drugs \\
\hline \multirow[t]{3}{*}{2} & Metal based therapeutic agents & \\
\hline & & Antiarthritic drugs \\
\hline & & Radiopharmaceuticals \\
\hline \multirow[t]{3}{*}{3} & Metal based diagnostic tools & \\
\hline & & $\begin{array}{l}\text { Contrast agents for Magnetic Resonance imaging (MRI) } \\
\text { Metalloenzyme inhibition }\end{array}$ \\
\hline & & Insulin mimetis \\
\hline \multirow[t]{4}{*}{4} & Biological targets for metal based therapies & Nitric oxide and superoxide \\
\hline & & Antimicrobials \\
\hline & & Chelation therapy \\
\hline & & Polyoxometallates in medicine \\
\hline \multirow[t]{2}{*}{5} & The future of bio-inorganic chemistry & \\
\hline & & A possible inorganic origin of life \\
\hline
\end{tabular}

Table 2 Functions of metal ions in biology $y^{30}$

\begin{tabular}{lll}
\hline Metal & Function & Typical deficiency symptoms \\
\hline $\mathrm{Na}, \mathrm{K}$ & Charge carrier, osmotic balance & Death \\
$\mathrm{Mg}$ & Structure, hydrolase, isomerase & Muscle cramps \\
$\mathrm{Ca}$ & Structure, trigger, charge carrier & Retarded skeletal growth \\
$\mathrm{V}$ & Nitrogen fixation, oxidase & $\mathrm{N} / \mathrm{A}$ \\
$\mathrm{Cr}$ & Glucose intolerance & Diabetes symptoms \\
$\mathrm{Mo}$ & $\mathrm{N}_{2}$ fixation, oxidase, oxo transfer & Retardation of cell growth \\
$\mathrm{Mn}$ & Photosynthesis, oxidase, structure & Infertility, impaired growth \\
$\mathrm{Co}$ & $\mathrm{Oxidase}_{\mathrm{i}}$ carbon group transfer & Pernicious anaemia \\
$\mathrm{Fe}$ & $\mathrm{O}_{2}$ transport and storage, oxidase, electron transfer, $\mathrm{N}_{2}$ & Anaemia, disorders of the immune system \\
$\mathrm{Ni}$ & fixation & Growth depression dermatitis \\
$\mathrm{Cu}$ & Hydrogenase, hydrolase & Artery weakness, liver disorders \\
$\mathrm{Zn}$ & Structure, hydrolase, male fertility & Skin damage, stunted growth, retarded sexual maturation, \\
$\mathrm{Se}, \mathrm{As}$ & Puberty and grown & impaired development \\
\hline
\end{tabular}

Table 3 Why are metal ions important in biology? ? $^{30}$

\begin{tabular}{ll}
\hline Topic & Kind \\
\hline Catalysing reactions via & Hydrolytic \\
& $\begin{array}{l}\text { Substrate transfer } \\
\text { Electron transfer } \\
\text { Protein }\end{array}$ \\
& DNA \\
Stabilizing structure & Skeletal \\
& $\begin{array}{l}\text { Osmotic balance } \\
\text { Charge balancing }\end{array}$ \\
Replication and information encoding
\end{tabular}


Table 4 Chemical considerations ${ }^{30}$

\begin{tabular}{ll}
\hline Espects & Factors influencing \\
\hline Linetics & Oxidation state \\
\hline Ligand Exchange rates & Geometry \\
& Electron configuration (e.g. Jahn Teller) \\
& Ligand effects \\
Complex stability and formation constant & Oxidation state \\
& HSAB theory \\
& Crystal field parameters \\
& Ligand field parameters
\end{tabular}

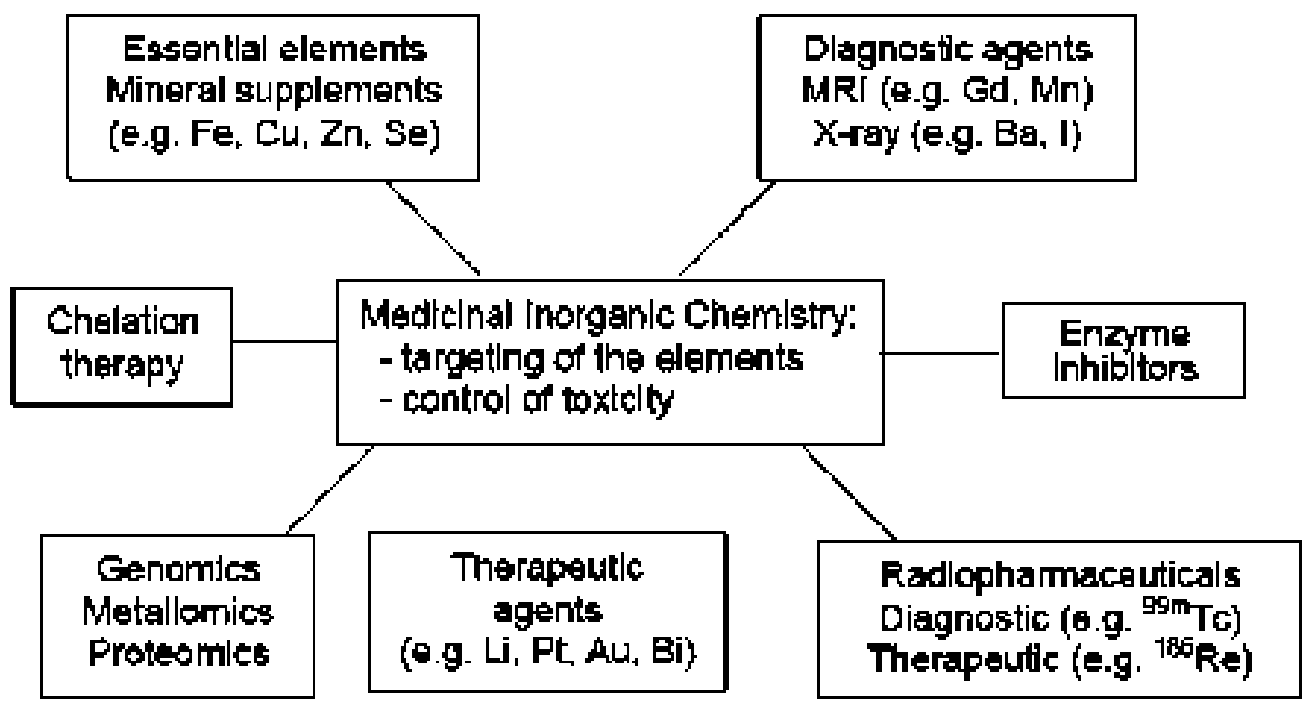

Figure 3 Some of the areas of medicinal inorganic chemistry. ${ }^{34}$

The successful case of cisplatin in the treatment of various kinds of neoplasms has positioned metal-based drug coordination chemistry at the forefront of the fight against cancer. ${ }^{38}$ Limit dose side effects or the appearance of acquired resistance are the limiting factor in the treatment with cisplatin. In this sense, the introduction of new Pt drugs has modified the situation, at least partially. This led to the development of carboplatin and other platinum-based cytotoxic drugs. Unfortunately, some platinum-based drugs developed as a result of shortcomings emanating from the clinical use of cisplatin were also associated with severe side effects that had prevented regulatory authorities from granting their marketing approval. ${ }^{39}$ Similarly, gold (III) complexes have been found to exhibit toxic effects; the most adverse cases of gold complex toxicity are restricted to skin and mucous membrane as reported in case of blind clinical trial. ${ }^{40}$ In a related development, increased ceruloplasmin and copper levels in various tissues have been associated with cancer progression. ${ }^{41}$ Most of these adverse effects are dose related and can be circumvented by structural modification of the metal-based complexes to enhance selectivity and reduce unwanted effects on normal cells. ${ }^{42-45}$ The search of solutions to these problems has encouraged a intense research in order to give a response to the urgent necessity of developing alternative strategies directed to different targets, by using varying metals, allowing improving the pharmacological features. The use of nanoparticles provide an advanced bioavailability, in vivo stability, intestinal absorption, solubility, sustained and targeted delivery and therapeutic effectiveness of several anticancer drugs generating a big challenge in the dosing of metal-based complexes in cancer therapy. ${ }^{42}$ Therefore, the opportunity provided by nanoparticles to selectively target cancer cells has gained interest in the design of metal-based cytotoxic drugs. 


\section{Chelating agents in the treatment of metallic ion overload in the body: brief historical}

The use of chelating agents to combat the toxicity of metals and metalloids dates back to the beginning of the last century (Alfred Werner, Paul Ehrlich, Carl Voeftin). The aim was decreasing the arsenic and antimony-containing drugs toxicity used in the treatment of parasitic maladies such as syphilis, trypanosomiasis and schistosomiasis. ${ }^{46,47}$ Low molecular weight chelating agents were applied in order to alleviate the effect of heavy metal and metalloid accumulation. The use of chelating agents to alleviate fortuitous exposures to metal ions begins in 1941 with the (questionable) use of citrate for lead poisoning.

The most evident medicinal application of chelating agents is the handling of metal accumulation cases. ${ }^{21,2,48-55}$ This use has been centred on the complexation and elimination of metals from the human body, such as $\mathrm{Pb}, \mathrm{Hg}, \mathrm{Sb}$ and As. Given the characteristics of these metals, most of the first ligands used for this purpose (Figure 4$)^{46}$ have sulphur as donor atoms.

2,3-Dimercaptopropanol known as British anti-Lewisite (BAL) dates from 1940. It is an antidote to Lewisite (dichlorovinylase), although it was never used as a war weapon. The first use of BAL was associated with arsenical therapies against syphilis and industrial accidents with arsenic. BAL, less toxic, more hydrophilic analogues: meso-2,3-dimercaptosuccinic acid (DMSA), and DL-2,3-dimercapro1-propanesulfonic acid (DMPS) appear later, being registered in some countries for use in mercurial poisoning treatment.<smiles>CC(C)(S)[C@H](N)C(=O)O</smiles>

D-Penicillamine<smiles>NCCNCCNCCN</smiles>

Triothylonctetmamine<smiles>C[As](=O)(O)O[Mg]</smiles><smiles>CC(O)CNCCN(CC(=O)O)CC(=O)O</smiles><smiles>CC(=O)CN(CCN(CCO)CC(=O)O)CC(=O)O</smiles>

Figure 4 Pro-ligands used to treat accumulation and cases of intoxication. ${ }^{46}$

The need of using lipophilic BAL painful intramuscular injections, led to the obtainment of an orally active copper chelating agent, (2S)-2-amino-3-methyl-3-sulfanyl-butanoic acid or D-penicillamine (D-pen). Ethylenediaminetetraacetic acid (EDTA), introduced in 1950 for the lead poisoning and for accidental cases involving radionuclides, was the next used in clinical practice. EDTA was substituted later by diethylenetriamine pentacetic acid (DTPA) mainly for the removal of radionuclides. The introduction of triethylenetetramine for patients with Wilson's disease intolerant to D-penicillamine dates from the 1980s. Although its power is less, it is an efficient substitute to the D-pen and for some experts the first choice. Deferoxamine has been the standard chelating agent most used in the treatment of iron accumulation since 1970; the derivative pyridone deferiprone (L1), and the tridentazo deferasirox agent (ICL 670) found oral use for the same purpose in the 80 s and 90 s, respectively.

Figure 5 shows the chelating agents approved (clinically verified) for the FDA in case of metals overload. The species being subject of removing may be a native metal, such as $\mathrm{Fe}$ or $\mathrm{Cu}$, o a contaminant reaching the body in a fortuitous or accidental way, such as $\mathrm{As}, \mathrm{Hg}$ or $\mathrm{Pu}$. Chelate therapy function implies to stimulate the inhibition of transgressing metals, by first sequestering them in form of high affinity complex, which is excreted then through the liver or kidney. ${ }^{21,22}$

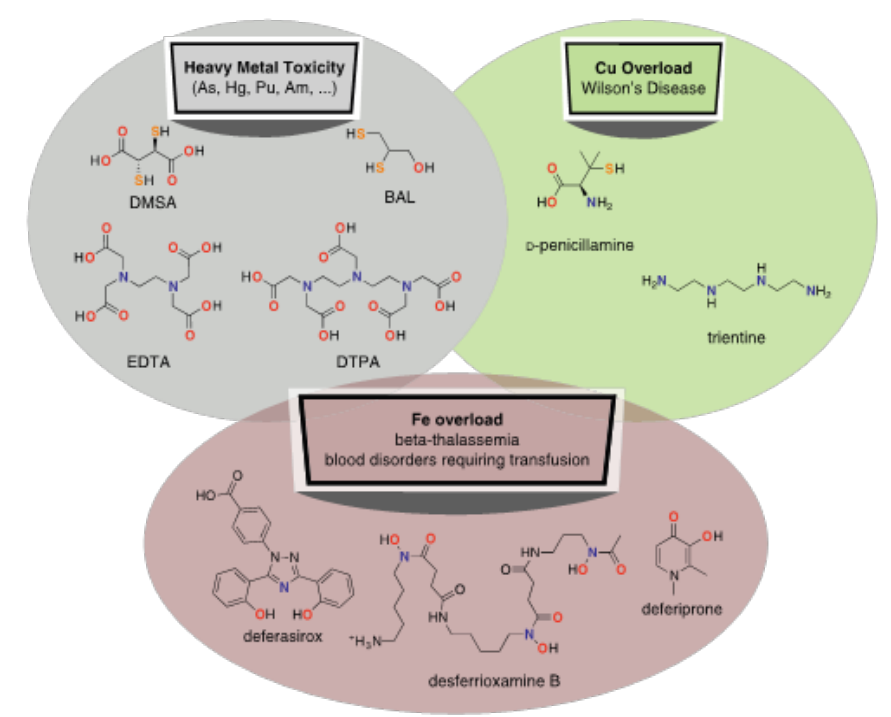

Figure 5 Chelating agents approved by the FDA for indications related to heavy metal toxicity, copper accumulation and iron accumulation. DMSA (meso, 2,3-dimercaptosuccinic); BAL (dimercaprol, meso-2,3-dimercaprol); EDTA (ethylenediaminetetraacetic acid); DTPA (diethylenetriaminepentaacetic acid); o-penicillamine (Cuprimine, Dpen, dPen); trientine (triethylenetetramine, trien; desderrioxamia B (DFO, deferoxamine, desferal); deferasirox (Exjade); and deferiprone (Ferriprox). 


\section{Expanding the notion of chelating agent in medicine.}

The classical therapy chelation notion involves the use of a chemical agent, administered with the purpose of removing a metal from the organism. ${ }^{21,22,54}$ However metal chelate formation can lead to biological implications that go beyond the simple elimination of the metal. ${ }^{16}$ The exploration of these possibilities can lead to therapeutically decisions (interventions) that vary the concentration, distribution, or reactivity of metals to achieve beneficial effects.

Four general strategies find use $\mathrm{e}^{16}$ in medicinal contexts beyond the usual concept of chelation therapy (Figure 6A):

a. The alteration of the biodistribution of the metal (Figure 6B), through biological membranes forming lipophilic complexes of a neutral character.

b. The specific inhibition of the metalloenzymes associated with the disease (Figure 6C), taking advantage of the chelation of the metal to form ternary complexes protein-metal-agent chelate.

c. Improving the reactivity of a complex to generate cytotoxicity, forming a complex chelate (Figure 6D), for example, which prevents Fenton chemistry in which a redox cycle catalyzes the formation of reactive oxygen species.

d. And conversely, the passivation of the reactivity of the metals to prevent cytotoxicity (Figure $6 \mathrm{E}$ ) by activation by chelation of an active centre.

(a) Eliminate toxic metals

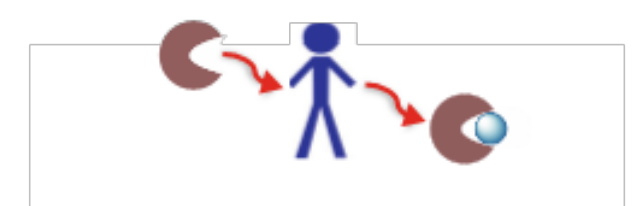

(b) Redistribute metals

(c) Inhibit metalloenzyme function
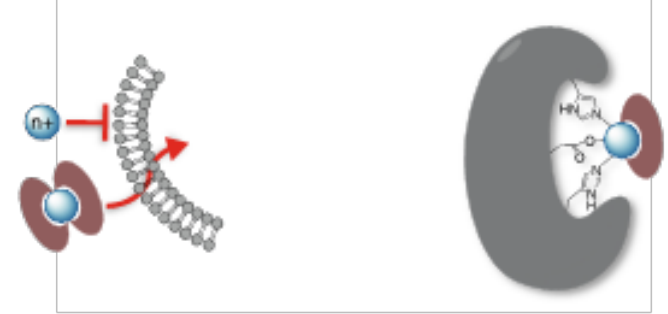

(d) Enhance metal reactivity

(e) Passivate metal reactivity
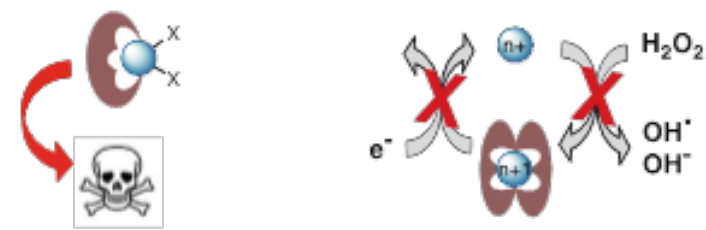

Figure 6 Chelation use strategies in the medicinal context. ${ }^{16}$

In recent decades, the hypothesis has been deepened that chemically defined chelating agents may be potentially useful in the treatment of ${ }^{6,55-57}$ neurodegenerative diseases. The moderate success of the bidentate chelating antimicrobial agent clioquinol has contributed to an increase in their use. Although its use in Alzheimer's disease started from the classic idea of sequestering agent, the mechanism of biological action is much more complex. ${ }^{58-60}$ It has been observed "in vitro" that $\mathrm{Cu}^{2+}$ and $\mathrm{Zn}^{2+}$ raise the disintegration speed of beta amyloid (A) peptide, preventing compounds such as clioquinol this process, even "in vivo". Clioquinol (Figure 7A), ${ }^{16}$ acts as an ionophore that may transport ions through biological membranes.

Well-designed inhibitors using chelating agents allow occupying the metal coordination positions blocking access to the substrate and thus interrupting the catalytic functions. RCD-5 inhibits HIV integrase by binding to the active position of the enzyme di-magnesium, via chelating 3-oxygens (Figure 7B). ${ }^{16}$ The rapid proliferation of cancer cells demands iron, so chelation on this way can be an efficient anticancer strategy. However, the biological effects of iron potent anticancer chelating agents with potent anticancer activity are complex, and linked to its redox activity, not with iron depletion. The chelating agent Dp44mT (Figure 7C), ${ }^{16}$ with potent antitumor activity, is an interesting example. The elesclomol (Figure 7D), ${ }^{16}$ evaluated in clinical trials, seems to work in an analogous way to mechanism related with copper. On the other hand, a masking group can first block the binding position realising then the chelating unit by an activation means. ${ }^{16}$ (a)<smiles>Oc1c(I)cc(Cl)c2cccnc12</smiles>
clioquinol

(c)<smiles>CCN(C)C(=S)NN=C(c1ccccn1)c1ccccn1</smiles>

Dp44mT (b)<smiles>Cc1cc(=O)c(O)c(C(=O)NCc2ccc(F)cc2)o1</smiles>

RCD-5 d)<smiles>CN(NC(=O)CC(=O)NN(C)C(=S)c1ccccc1)C(=S)c1ccccc1</smiles>

elesclomal
Figure 7 Special chelating agents mentioned in the text. ${ }^{16}$

\section{Ion metal complexes of medicinal interest}

Next, a brief description of main ion metal complexes having medicinal interest is presented. Metal ions play important roles in biological processes, and the field of knowledge concerned with the application of inorganic chemistry to therapy or diagnosis of disease is medicinal inorganic chemistry. ${ }^{11}$ Platinum, gold, iron, copper and aluminium are considered in this context.

\section{Platinum}

In the 1960s it was found that cis-diaminodichloroplatinum (II), or cisplatin, inhibits the cell division of Esterichia Coli leading to the ensuing discovery of the effective antitumor capacity in mouse models of this simple coordination compound. ${ }^{34,38,61,62}$ Cisplatin was validated later in humans, approving the FDA its use for the treatment of testicular and ovarian cancer in 1978. Its introduction in the therapeutically arsenal improves the survival prospects of many cancer patients. The 
cure of testicular cancer with modern platinum chemotherapy went from less than $10 \%$ before its introduction, to $90 \%$. Cisplatin kills cancer cells by cross-linking with the DNA strand and inhibition of transcription phenomenon. Despite the curative success with this kind of cancer, cisplatin is not universally effective against other types of cancer provoking a number of side effects. In addition, certain types of cancer resist to therapy with cisplatin. The resistance may be either intrinsic or it may appears after a prolonged treatment. To overcome these difficulties, new platinum complexes have been devised and their anti-tumour properties investigated. . $112,38,63$ Although thousands of compounds have been prepared and tested, very few are approved for clinical use (Figure 8). ${ }^{38}$

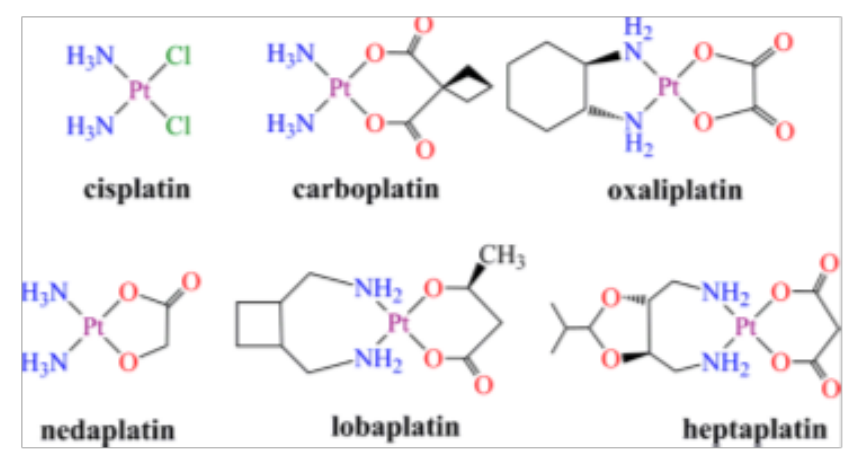

Figure 8 Chemical structures of anticancer drugs for clinical use based on platinum. The complexes of the upper part are approved all over the world; those at the bottom are approved in Japan, China, and Korea, respectively. ${ }^{38}$

Pt (IV) complexes enter the medical scenario shortly after cisplatin toxicity became a major clinical problem. ${ }^{61}$ It is believed that the octahedral complexes of Pt (IV) are kinetically more inert in the bloodstream, but can be activated by reducing agents once they penetrate the cells, originating cytotoxic species of Pt (II). They have the advantage with respect to the compounds of Pt (II), of oral availability and reduced resistance and toxicity. They offer an advantage over Pt (II) compounds such as oral availability and reduced resistance and toxicity.

Thousands of Pt (IV) complexes synthesized have been evaluated in the context of prodrugs. The two best-known examples are satraplatin (JM216) and LA-12. The satraplatin (Figure 9), ${ }^{61}$ is in an advanced clinical trial for prostate, lung and ovarian cancer; it is activated in the presence of intracellular reducing agents such as glutathione and ascorbic acid, among others, and shows little neurotoxicity, neurotoxicity and cytotoxicity. LA-12 (Figure 9), ${ }^{61}$ is an analogue of satraplatin containing a bulky hydrophobic ligand, adamantylamine, which can potentially increase the release of LA-12 by cancer cells, being efficient against ovarian carcinomas resistant to cisplatin, in a significative way.

BBR 3464 (Figure 9), ${ }^{61}$ a charged polynuclear complex, is more potent than cisplatin and shows good activity against resistant cell lines. Clinical trials (the only proven compound not based on the cisplatin chemotype) began in June 1998 and are currently progressing in Phase III (treatment of patients with melanoma, pancreas, lung, ovary, and gastric tumours). The complex consists of two monofunctional Pt moieties and forms wide-range cross-linked adducts. Multinuclear complexes of Pt (II) offer different reactivities and biological activities than cisplatin and analogues. ${ }^{61}$ Ruthenium has several oxidation states $(2+, 3+$ and $4+)$ that can coexist under physiological conditions. The ruthenium complexes have the same kinetic spectrum of substitution of ligands as the Pt (II) complexes in aqueous medium, being therefore appropriate alternatives to the anti-cancer drugs of Pt (II). In recent decades, the activity of various ruthenium complexes $(2+$ and $3+)$ has been synthesized and studied against several model tumours, but only real progress is made with the arrival of NAMI-A and KP 1019, currently under clinical trials These complexes are particularly useful in the treatment of metaplastic tumours resistant to cisplatin. ${ }^{61}$ (a)<smiles>CC(=O)O[P+](N)(Cl)(Cl)(Cl)OC(C)=O</smiles><smiles>CC(=O)O[PH](N)(Cl)(Cl)NC12CC3CC(CC(C3)C1)C2</smiles><smiles>CCCCNP(N)(N)(Cl)NCCCCCCN[PH](N)(N)NCCCCCCN[PH](N)(N)Cl</smiles>

BBR3464

Figure 9 (A) JM2 I6 (Satraplatin); (B) LA- 12; y BBR3464..$^{54}$

\section{Gold}

Among the non-Pt anti-tumour agents, gold complexes have received in the last decades an increasing attention due to their great inhibitory effect on the growth of tumour cells, being able to exploit their pharmacodynamics and pharmacokinetics properties and their mechanisms of action..$^{34}$ In recent decades, new compounds of Au (I) and $\mathrm{Au}$ (III) with different molecular structures have been developed and tested as anticancer agents. Gold complexes with phosphine, carbene, diethyldithiocarbamate ligands, and porphyrinates have been the most investigated, "in vitro" and "in vivo". Although its mechanisms of action have yet to be elucidated, some relevant biochemical properties of gold complexes are common. For example, the inhibition of thioredoxin reductase, binding to protein and DNA, the triggering of anti mitochondrial effects and the induction of apoptotic events, among others, have been confirmed for different gold compounds, which contribute to their pharmacological profiles. ${ }^{61}$

Gold complexes such as auronofin (Figure 10), ${ }^{19,46}$ formulated for oral use, unlike their injectable precursors, e.g. gold sodium thiomalate, are administered in the treatment of rheumatoid arthritis. Although the mechanisms of the therapeutic (and toxicological) effects are still uncertain, it is thought that auranofin carries out immunosuppression by a variety of actions. The gold compounds were first applied ${ }^{47}$ in the treatment of rheumatoid arthritis in 1927, and are still applied in the treatment of severe cases.

\section{Iron}

Oxygen is transported in the blood by haemoglobin, an iron- 
containing protein, which is composed of two subunits called $\alpha$ and $\beta$. The $\beta$-thalassemia is a genetic disorder that affects more than 100,000 children each year, consisting of the fact that haemoglobin units are not synthesized in adequate amounts, which translates into anaemia. ${ }^{64-67}$ Children affected by the disease survive only with the frequent transfusion of red blood cells. The result of continuous blood transfusions is the toxic accumulation of iron in the body.
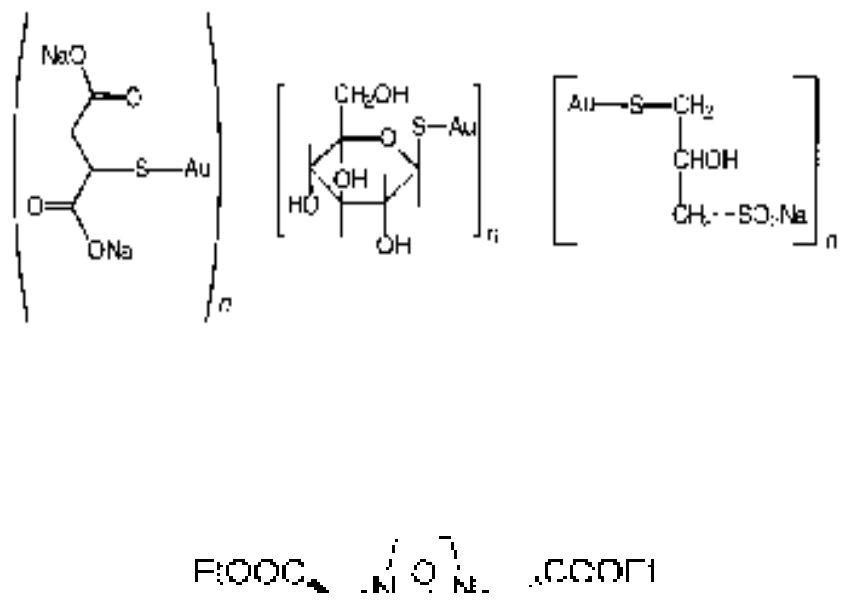

Figure I 0 From left to right:Polymeric complexes of Myocrisin (aurothiomalate sodium), Solganol (aurothioglucose), Allocrysine (auroptopanolsulfonate sodium); and Ridaura (auranofin), the only oral antiarthritic compound for oral clinical use. ${ }^{19,39}$

The total iron in the body of the healthy man is maintained at a constant level of about $4-5 \mathrm{~g}$, the daily absorption (1-3mg) being balanced with the average daily loss in an equivalent amount. A severe iron deficiency in the diet can affect the synthesis of haemoglobin resulting in anaemia, but in most cases it is easily treated with iron supplements. Serious toxic effects that are more difficult to treat arise as a result of an excess of iron in the body, which is known as iron overload. Some thalassemic patients can accumulate 40 to $50 \mathrm{~g}$ of iron in a period of 10 years. ${ }^{66}$ This is a threat to life since iron, by virtue of its easy redox chemistry, is toxic when it occurs in excess, lacking the organism lacks mechanisms of excretion of large quantities of it.

The (intensive) therapy consists in the treatment with chelating agents to clean the organism of excess accumulated toxic iron, having successfully used desferrioxamine B, a powerful chelating agent of $\mathrm{Fe}^{3+}$, produced by Streptomyces pilosus. This molecule is quite selective for iron, showing much lower affinities for copper, zinc, calcium and magnesium. ${ }^{66}$ Given its high solubility in water, it is capable of selectively removing iron and facilitating its excretion by bile and urine. However, it has the disadvantage of being inactive orally and only works well when administered subcutaneously or intravenously in periods of 8-12 hours up to six times a week. This makes it difficult to comply with the treatment. Hence the intense search for active chelating agents by mouth.

The obvious method of choice when designing new selective iron chelating agents is to model compounds based on natural siderophile structures. Like all living cells, microorganisms require iron as an essential nutrient, being this metal a cofactor of numerous enzymes and respiratory proteins. Siderophores are compounds of low molecular weight (500 to $1000 \mathrm{Da}$ ) with very high affinities towards iron. The coordination of the metal occurs in most cases via oxygen atoms, either from the hydroxamate or catechol groups. However, these functional groups have disadvantages for their clinical application.

The hydroxamates are sensitive to the acidic environment of the stomach, some being subjected to breakage catalyzed by enzyme, while the catechols are rapidly oxidized in the intestine and also poorly absorbed. Attempts to overcome these difficulties led to the design of non-hydrolysable analogues of the natural siderophore enterobactin, but many of its derivatives are insoluble in water. Although this latter limitation can be overcome by introducing sulphonate groups, the absorption of the resulting high charge derivatives is then very low. An additional drawback of the tricatechol type ligands is that they lead to the formation of charged complexes of iron (III), trapping the metal intracellularly and thus preventing its excretion.

Traditionally, polycarboxylic ligands have been used to chelate transition metals, including iron (III). However, these chelators are not specific enough for iron, and their use in the body in chelation therapy can lead to the elimination of other essential metals, for example calcium and zinc. This is why a systematic search has been undertaken for molecules that possess the characteristic selectivity for iron of hydroxamates and catechols, and that lack their disadvantages. ${ }^{66}$ In particular, neutral ligands are searched, e.g. hydroxypyridones, which give rise to neutral iron complexes, which are absorbed in the gastrointestinal tract and are capable of penetrating the cells, at the same time that the resulting neutral complex freely exudes from them. Clinically, useful iron chelating agents should be able to get iron not bound to proteins, but not with iron bound to enzymes, redox proteins and oxygen carriers, since they could interfere with cell function in their normal case and induce an ample spectrum of undesirable side effects. Desferrioxamine reduces the incidence of heart and liver diseases in patients with thalassemia. In those in which iron accumulation is effectively controlled, $91 \%$ survival is free from heart disease after 15 years of treatment. ${ }^{67}$ Many potent iron-chelating agents have been tried, although very few have been introduced into clinical practice. Deferiprone (Figure 5), introduced in 1987, has been used with positive effects in more than 50 countries (but its use is not allowed in Canada and the United States). The structure and activity of deferiprone and other 3-hydroxy-4-pyridones used in chelation therapy against iron accumulation has been studied by computational and optical methods. ${ }^{68}$ Specific iron chelating agents (CSI) can be used in the healing of neurodegenerative processes such as Alzheimer's, Parkinson's and prion diseases, in which iron plays a significant role. The combined use of desferroxyamine and deferiprone increases survival and reduces heart disease in relation to the isolated use of each of them. In 2005, a chelating agent for oral use, deferasirox (Figure 5), was approved in the United States. No current treatment is totally effective; hence the interest that this field of work awakens (Table 1). In the long term, bone marrow transplantation or gene therapy could cure the disease.

\section{Copper}

Copper is an essential element for life; many enzymes contain copper. ${ }^{69}$ Copper acts as a catalytic and structural cofactor, and consequently intervening on this way in a variety of biological routes. Since copper is necessary for the activity of these enzymes involved in normal metabolism, and is not synthesized by any biochemical process, its inclusion as a dietary component is essential. For these reasons, much attention has been given to the investigation of its mechanisms of absorption, distribution, metabolism and excretion. 
Attention has also been paid to clarify its function in the development of cancer and other diseases. The bioavailability of copper is depending ${ }^{70}$ on varying factors, fundamentally:

a) The copper absorption in the gastrointestinal tract.

b) The transportation of copper to the bloodstream.

c) Its extraction of by hepatocytes from the bloodstream.

d) The uptake of copper by peripheral tissues and the central nervous system.

The fundamental aspects of copper chemistry and biochemistry, the role of copper in medicine, the pathology and treatment of Menken and Wilson's diseases, and chelation therapy in neurodegenerative disorders involving their accumulation have been treated with detail $^{41,71,72}$ in recent reviews. The readers may consult these sources to obtain an in-depth understanding of the multifaceted roles that copper ion plays in physiology.

The concentration of copper in the human body is closely regulated at the level of cells, organs and body, since free copper ions are potentially detrimental. Once copper is absorbed in the stomach and small intestine, its distribution in the bloodstream is regulated in the liver by ceruloplasmin and albumin. Complex control mechanisms transport copper then through cell membranes fundamentally via copper transporter protein (CTR1) during import and $\mathrm{Cu}$ ATP7A/B during export. ${ }^{36}$ All these proteins have many residues (mainly methionine, histidine and cysteine) to which copper is co-ordinated.

The copper complexes in particular are remarkable active pharmacological agents, activity that we can compare with that of the isolated copper ions or that of the free ligands. An increase of the compounds containing copper in the blood plasma, amino acids and albumin and ceruloplasmin complexes is observed as part of a general physiological response to disease states such as infections, arthritis, epilepsy and cancer. Copper may reaches a concentration of $1.67 \mathrm{mg} / \mathrm{L}$ in the serum of patients with breast cancer, concentration greater than $0.98 \mathrm{mg} / \mathrm{L}$, the normal reference. When the disease is overcome, copper levels return to normal.

Wilson's disease, i.e. hepatolenticular degeneration, is a metabolic disorder featured by copper accumulation in different organs, yielding liver cirrhosis, neurological disturbances and a complexity of symptoms related to the mismatch of the transport and distribution of copper throughout the organism (frequently affected patients have low levels of ceruloplasmin) in serum. Different chelating agents have been used in clinical practice in therapy. ${ }^{70}$

Copper complexation is a strategy that can be used for tumour reversion; tumour cells constitute a proper, selective target for an antitumor drug. The donor ligand atom is of vital worth as it may modulate:

a) The properties of the metal.

b) The lipophilic-hydrophilic balance of the resulting complexes.

c) Their solubility in the extracellular fluids as well as the ability to traverse the lipid membrane of two layers.

The stability towards transchelation reactions with physiological molecules (individual amino acids, peculiar peptide sequences, or proteins) should also be subject of consideration in designing copper complexes. Many of them have been proposed as promising cytotoxic agents on the basis of in vitro tests. However very little data concerning with their mechanisms of action have been the subject of publication.

Currently, the control of angiogenesis, tumour growth, and metastasis can be achieved by chelating the copper excess. ${ }^{36}$ Small molecules with the ability to bind copper have been synthesized and structurally manipulated (Figure 5), e.g. trientine (trien), D-pen and tetrathiomolybdate (TM). Though copper chelators have been exploited as potential therapeutic agents for some types of cancers, their clinical approval have been usually circumscribed to patients with heavy metal poisoning or diseases with a severe metal accumulation (Wilson's disease). It has recently been shown that mixtures of copper salts with dithiocarbamates (DTC) or clionicol (CQ) spontaneously bind with the cell tumour copper forming a proteosome inhibitor and an inducer of apoptosis. The penicillamine complexes with $\mathrm{Cu}$ (II) (benzylpenicillin, phenoxymethylene-penicillin, ampicillin, amoxicillin, and carbanicilin) show stoichiometries of type 1:1, $1: 2$ and $1: 3$. The structure of the compounds behaves as bidentate ligands coordinated by the $\mathrm{Cu}$ (II) ion through the carboxyl groups. The copper (II) ions promote the hydrolysis of penicillin to the corresponding penicilloic acids, due to the $\beta$-lactam group. This same process $^{28}$ has been confirmed for $\mathrm{Cu}$ (II) ions and carboxyl groups of cefazolin, which also belongs to the family of lactam-antibiotics. Bisthiosemicarbazone. ${ }^{56,73-77}$

\section{Aluminium}

Aluminium compounds find a wide use in the food, textile, dye and paper industry, as well as in cosmetic and pharmaceutical preparations, and in human and veterinary medicine. ${ }^{78} \mathrm{~A}$ buffered aspirin with aluminium glycinate, for example, has use as an analgesic. The atmospheric acidification is a progressive cause of a massive transport via acid rain of aluminium from the mountains (mineral deposits) to the surfaces of the waters, exposing plant, animal and man species, to interact with cationic absorbable Al species. ${ }^{79,80}$ Aluminium products were widely used in all human activities until the 70's, date in which was considered as origin of different diseases, especially osteodystrophy and dementia in patients with kidney failure under dialysis treatment. The knowledge of the toxicity of $\mathrm{Al}$ led to a substantial rising in the chemical and biochemical research of this metal ion. ${ }^{81}$ The hydrolytic chemistry of aluminium greatly affects its solubility and bioavailability in biological media. The speciation of the equilibria of the different forms of aluminium hydroxocomplexes, either soluble or insoluble, together with other competitive ligand complexes formed, must be taken into account to explain its solution in biological systems. ${ }^{79-81}$

The accumulation of aluminium in the body is not common, but it can come from physiological disorders that can give rise to an excess of aluminium compared to its slow natural process of elimination. Today the syndrome of dialytic encephalopathy is less common due to the absence of aluminium in dialysis equipment. The accumulation of aluminium is also of interest because excessive amounts of it are present in patients suffering from Alzheimer (the causes are not clear and may be a mere side effect). Desferriferrioxamine-B (desferal, DFO), ${ }^{80}$ a microbial siderophile that has been widely used in the treatment of Cooley's anaemia and other forms of iron accumulation, is recommended for the treatment of $\mathrm{Al}(\mathrm{III})$ accumulation. The pyridone L1 also has a high affinity for aluminium and can also be used to remove excess aluminium in the human body. 


\section{Selected applications}

The following is a tabular summary of the contents of works related to the use of ligands and complexes of therapeutic interest, paying attention to the most relevant and current bibliography. Table

5 is ordered on the basis of the most frequently studied metal ions. Table 6 contains a miscellany of topics based on selected key words, of interest in the subject that concerns us.

Table 5 Selected reviews on applications of ligands and / or complexes of therapeutic interest

\begin{tabular}{|c|c|}
\hline Metal & Comment \\
\hline \multirow{9}{*}{$\mathrm{Pt}$} & Metallointerlators based on the use of Platinum ${ }^{82}$ \\
\hline & Anticancer agents based on Platinum ${ }^{83}$ \\
\hline & New platinum compounds based on bidentate ligands $O, S^{84}$ \\
\hline & Synthetic methods for the preparation of anticancer platinum complexes ${ }^{38}$ \\
\hline & Anticancer compounds based on platinum ${ }^{85}$ \\
\hline & Distribution of Platinum drugs in cancer cells and tumours ${ }^{86}$ \\
\hline & From platinum to gold-dithiocarbamate complexes in cancer therapy $y^{34}$ \\
\hline & Current status of antitumor drugs based on Platinum ${ }^{87}$ \\
\hline & $\mathrm{Pt}\left(\mathrm{NH}_{3}\right)_{2} \mathrm{Cl}_{2}$ and cancer ${ }^{88}$ \\
\hline \multirow{2}{*}{$\mathrm{Au}$} & Prospects for the future of organometallic gold complexes ${ }^{89}$ \\
\hline & Therapeutic agents based on gold ${ }^{90}$ \\
\hline \multirow{17}{*}{$\mathrm{Fe}$} & Fe brain therapy by iron chelation of deferasirox-lactoferrin conjugates ${ }^{57}$ \\
\hline & Iron chelating agents in photodynamic therapy: synergistic effect of active thiosemicarbazones ${ }^{91}$ \\
\hline & Chelating agents for the systemic treatment of iron accumulation ${ }^{92}$ \\
\hline & Design of iron chelating agents with therapeutic applications ${ }^{93}$ \\
\hline & Designs of macromolecular iron chelating agents of clinical utility ${ }^{94}$ \\
\hline & Iron chelating agents in the treatment of iron accumulation ${ }^{95}$ \\
\hline & Chelating properties of new 3-hydroxypyridin-4-one ${ }^{96}$ \\
\hline & Iron bound to non-transferrin and iron-citrate complexes in thalassemic serum ${ }^{97}$ \\
\hline & Chelating agents in the treatment of disorders due to iron accumulation ${ }^{98}$ \\
\hline & Toxicity and modes of action and future possibilities of iron chelating agents ${ }^{99}$ \\
\hline & Chelation of iron under physiological conditions ${ }^{100}$ \\
\hline & Chelating agents of iron in clinical practice ${ }^{101}$ \\
\hline & Iron chelation therapy ${ }^{66}$ \\
\hline & Iron: nutrient and poison ${ }^{102}$ \\
\hline & Iron chelation therapy $y^{20}$ \\
\hline & Thiosemicarbazone and pyrazinylhydrazone of picolinaldehyde in iron accumulation ${ }^{103}$ \\
\hline & Chelation and metabolism of iron ${ }^{104}$ \\
\hline \multirow{6}{*}{ Al } & Chelating agents in aluminium accumulation ${ }^{78}$ \\
\hline & Perspectives in the chelation of aluminium and iron in the brain ${ }^{105}$ \\
\hline & In vitro and in vivo studies of hydroxypyridone complexes with aluminium ${ }^{106}$ \\
\hline & Speciation of aluminium in human serum 79 \\
\hline & Study models for aluminium and Alzheimer disease ${ }^{107}$ \\
\hline & Coordination of $\mathrm{Al}$ (III) in the environment and in biological systems ${ }^{80}$ \\
\hline
\end{tabular}




\begin{tabular}{|c|c|}
\hline Metal & Comment \\
\hline \multirow{12}{*}{$\mathrm{Cu}$} & $\begin{array}{l}\text { Control of redox potential and lipophilicity with } \mathrm{Cu}(\mathrm{II}) \text {-bisthiosemicarbazone complexes as PET } \\
\text { radiopharmaceuticals }^{73}\end{array}$ \\
\hline & Redox properties of therapeutics $\mathrm{Cu}(\mathrm{II})$-bisthiosemicarbazone complexes ${ }^{75}$ \\
\hline & $\mathrm{Cu}(\mathrm{II})$-bisthiosemicarbazone complexes as antibacterial agents ${ }^{74}$ \\
\hline & The multiple facets of copper in medicine and treatment $\mathrm{t}^{71}$ \\
\hline & Copper complexes as anticancer agents ${ }^{36}$ \\
\hline & Biochemical aspects of copper and its complexes in medicine ${ }^{41}$ \\
\hline & Copper related diseases ${ }^{70}$ \\
\hline & Copper-doxorubicin in cancer therapy ${ }^{108}$ \\
\hline & Dual behaviour of ionic copper in biology ${ }^{72}$ \\
\hline & Copper complexes as anticancer agents ${ }^{109}$ \\
\hline & Copper-thiomolybdate complexes in Wilson's disease ${ }^{110}$ \\
\hline & Copper complexes in Biochemistry and Pharmacology ${ }^{69}$ \\
\hline \multirow{4}{*}{ Gd } & Chelates of Gd (III) as contrast agents'II \\
\hline & Gadolinium complexes as contrast agents ${ }^{1 / 2}$ \\
\hline & New contrast agents MRI ${ }^{113}$ \\
\hline & Complexes of $\mathrm{Gd}(\mathrm{III})$ as contrast agents $\mathrm{MRI}^{37}$ \\
\hline $\mathrm{Pb}$ & Chelation therapy in lead poisoning: 3,3-dimercaptosuccinic acid ${ }^{114}$ \\
\hline $\mathrm{Hg}$ & Rational design of chelating agents for mercury ${ }^{115}$ \\
\hline $\mathrm{Hg} / \mathrm{Cd}$ & Chelation of Mercury and Cadmium; speciation, 2,3-Dimercaptosuccinic acid"16 \\
\hline \multicolumn{2}{|c|}{ Chelation therapy in intoxication by these metals ${ }^{117}$} \\
\hline $\mathrm{Te}$ & Tellurium poisoning: scientific coincidence ${ }^{118}$ \\
\hline $\operatorname{Re}(\mathrm{VII}) \mathrm{Tc}(\mathrm{VII})$ & Trioxo complexes of $\operatorname{Re}(\mathrm{VII})$ and Tc (VII) stabilized by tridentate ligands as radiopharmaceuticals ${ }^{119}$ \\
\hline $\mathrm{Zn}$ & New zinc complexes with heterocyclic ligands as antimicrobial agents ${ }^{120}$ \\
\hline $\mathrm{Bi}$ & Chelating nitrogen rich macrocyclic ligands of therapeutic bismuth radioisotopes ${ }^{121}$ \\
\hline \multicolumn{2}{|c|}{ Bioinorganic chemistry of bismuth and antimony: metallodrugs ${ }^{122}$} \\
\hline $\mathrm{Ti}$ & Bioinorganic chemistry of titanium ${ }^{24}$ \\
\hline \multirow{3}{*}{$\mathrm{Co}(\mathrm{II})$} & Cobalt compounds of multifaceted chemotherapeutic agents ${ }^{123}$ \\
\hline & Cobalt derivatives as therapeutic agents ${ }^{124}$ \\
\hline & Vitamin BI2, (cyanocobalamin): electronic structure ${ }^{125}$ \\
\hline \multirow{2}{*}{$\mathrm{Pu}$} & Activity and rational design of sequestering agents ${ }^{126}$ \\
\hline & Chelation "in vivo", mixed octodentate ligands based on spermine ${ }^{127}$ \\
\hline \multirow{5}{*}{ Lanthanides } & Complexes in leishmaniasis or Chagas disease ${ }^{128}$ \\
\hline & Lanthanide complexes in osteoporosis ${ }^{129}$ \\
\hline & Lanthanide compounds in bone resorption disorders ${ }^{130}$ \\
\hline & Therapeutic applications of lanthanides ${ }^{|3|}$ \\
\hline & Therapeutic agents radiopharmaceutical $\left.\right|^{132}$ \\
\hline
\end{tabular}


Table 6 Miscellaneous topics related to selected reviews on ligands and / or complexes of therapeutic interest

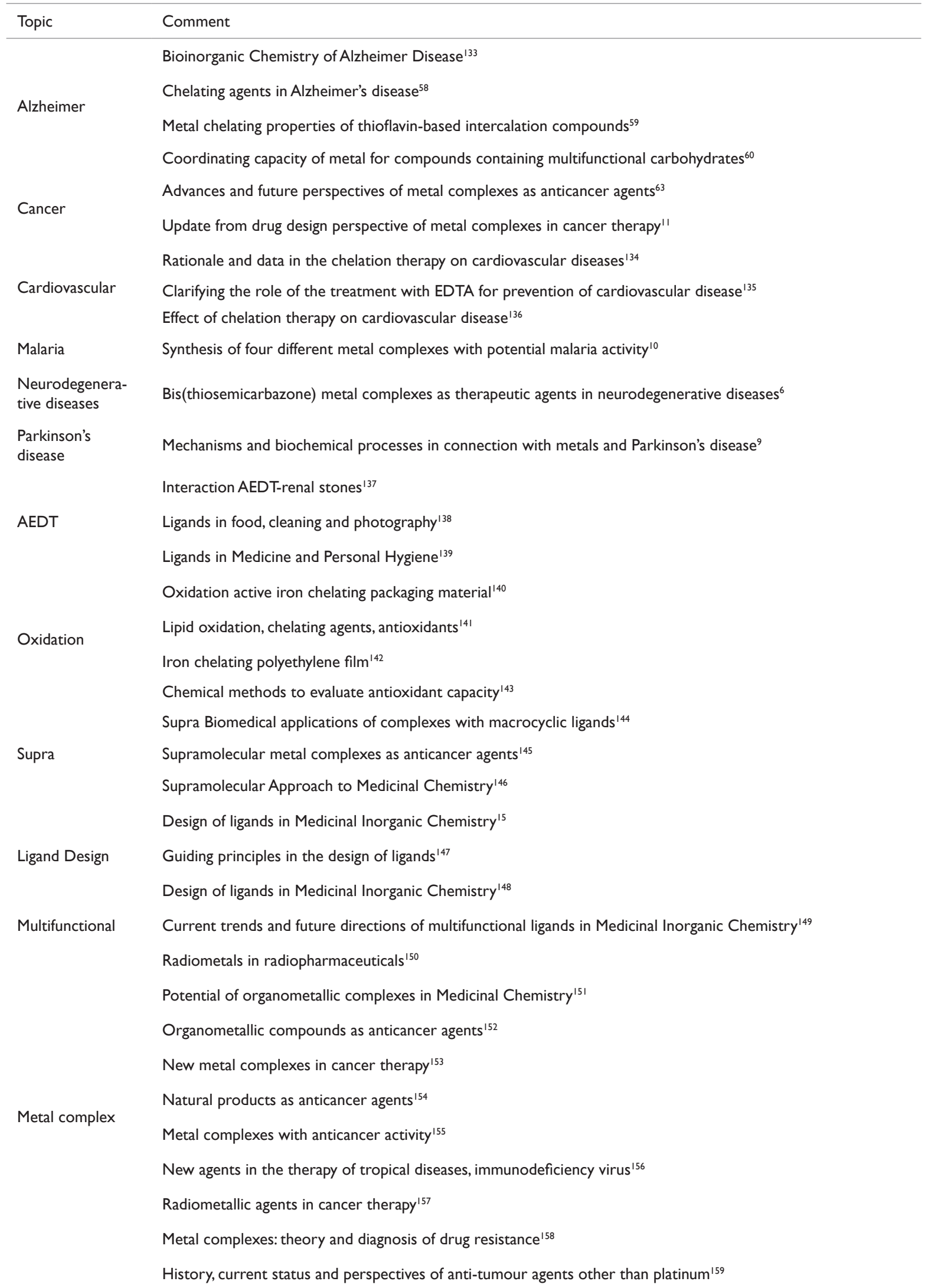




\begin{tabular}{ll} 
Table Continued & \\
\hline Topic & Comment \\
\hline Toxic metals & New strategies in the separation of toxic metals from soil and water ${ }^{160}$ \\
Environment & Chelating agents in the environment ${ }^{161}$ \\
Difosfonates & Hygiene products in health care ${ }^{162}$ \\
Chemical warfare & Degradation of chemical warfare agents through reactive polymers ${ }^{163}$
\end{tabular}

Summary of in vitro cytotoxic effect of various metal-based compounds with particular reference to their proposed mechanism of action, target and IC50 range "I

Role of copper and the recognition of its complexes as important bioactive compounds in vitro and in vivo as potential drugs for therapeutic intervention in various diseases ${ }^{41}$

Platinum anticancer drugs currently approved for use: clinical trials and results ${ }^{39}$

Dosing and Nanoparticles as drug delivery systems in cancer medicine.A challenge in the dosing of metal-based complexes toxicity in cancer therapy ${ }^{42}$

Toxicity of metal compounds: Basic concepts of toxicity studies and known data are described in a tutorial ${ }^{43}$

Clinical trial of dose escalation of lobaplatin in combination with fixed dose docetaxel for the treatment of human solid tumours ${ }^{44}$

Combination therapy together with redox modulators to increase the anticancer potency: attractive for lowering the doses of metal complexes that need to be administered ${ }^{45}$

\section{Final considerations}

Chemists and their compounds have contributed tremendously, ${ }^{164}$ without any doubt, to the impressive progress of medicine. The exploration of the chemistry of coordination offers real possibilities $^{5,8,31,151,164}$ for a new understanding of intractable diseases and for the design of novel therapeutic and diagnostic agents. The rational design of the chelating agents requires ${ }^{15,19,34}$ an understanding of link kinetics, catalysis mechanisms and donor interactions. Ligands can be introduced into a biological system to ${ }^{16}$ limit the adverse effect of the accumulation of a metal ion, to inhibit selected metalloenzymes, or facilitate the redistribution of a metal ion. Some of the mentioned effects involve the modification of reactivity and lipophilicity, stabilization of specific oxidation states or contributions to substitution kinetics. The rational design of efficient chelating agents requires ${ }^{58}$ a good knowledge of the electronic and molecular structure of the complexes formed.

The discovery (incidental) of the anti-cancer activity of cisplatin in 1960 and its subsequent clinical success generated great interest in the use of metal compounds, Pt and other elements ${ }^{34,61}$ in the treatment of cancer. The success achieved in this regard by the platinum complexes cisplatin, carboplatin and oxaliplatin has promoted the development of other possible alternatives to be taken into account. Carboplatin is less toxic than cisplatin and can be administered at much higher doses. Oxaliplatin finds use against tumors resistant to cisplatin. Pt (IV) complexes are less toxic than their Pt (II) counterparts and offer many possibilities ${ }^{61}$ for the rational design of drugs, including oral administration, versus intravenous drugs. Photosensitive Pt (IV) complexes can be activated in tumour tissues to reduce potential damage to healthy people. In addition to the separation of foreign toxic metals and metalloids that do not possess a native biological function, chelation therapy is also used to diminish the essential levels in case of copper and iron accumulation disorders. Given its relative rarity, there is less pressure to develop specific chelating agents $^{86}$ for the treatment of intoxications. Gadolinium complexes are contrast agents in MRI (about 20 million doses administered per year) and technetium radiopharmaceuticals used in ray image analysis (about 20 million diagnoses per year). ${ }^{35}$ In recent decades it has been suggested that chelating agents may be potentially useful in the treatment of neurodegenerative diseases or genetic disorders involving dishomeostasis.

The accumulation of iron can come from hemochromatosis, a family of genetic disorders consequence ${ }^{16,64,65}$ of an unregulated absorption of iron, or of successive blood transfusions necessary to treat blood diseases, ie,-thalassemia and cell disease sickle. Three chelating agents (ligands) have been approved for their treatment: desferrioxamine B, deferasinox and deferiprone. Desferrioxamine is clinically approved ${ }^{19}$ for the treatment of malaria. Its activity can come from the disruption of iron metabolism in the digestive vacuoles of malaria parasites. In Wilson's disease, the mutation of the ATP7B gene results in the blockage of normal copper traffic, ${ }^{36}$ leading to an accumulation of copper in the liver that finally spreads to other body organs including the brain. The painful treatment with BAL has given rise to D-penicillamine and triethylene tetramine.

The future of chelating agents designed for therapeutic use in the treatment of diseases evolves to the multifunctional approach. ${ }^{60,83,123,149}$ In any disease there are multiple biochemical aberrations that must be addressed, and although combination or cocktails of different therapeutic agents could be used for this purpose, a more desirable option is to integrate all these functionalities into a single molecule. For many centuries, the use of metallodrugs has been promoted by empiricism. ${ }^{26}$ While random screening is still a useful means of drug discovery, today these steps are guided by rational design. The tailor-made design of metal-based drugs to treat specific diseases and disorders is likely to be an important ${ }^{15,35}$ of the future of personalized medicine, which will include the genomic and proteomic profile of individuals. 


\section{Acknowledgements}

None.

\section{Conflict of interest}

The authors declare that there is no conflict of interest

\section{References}

1. Chellan P, Sadler PJ. The elements of life and medicines. Phil Trans A Math Phys Eng Sci. 2015;373:2037.

2. Lippard SJ. Metals in medicine. In: Bertini I, Gray HB, Lippard SJ, editors. Bioinorganic Chemistry. California: University Science Books; 1994. 505-583 p.

3. Sigel A, Sigel H. Metal Ions and their Complexes in Medication. In: Metal Ions in Biological Systems. Boca Raton: CRC Press; 2004. 600 p.

4. Spencer J, Walden B. Special focus: metals in medicine. Future Med Chem. 2017;10(6):607-609.

5. Carver PL. Essential Metals in Medicine, Therapeutic Use and Toxicity of Metal Ions in the Clinic. Berlin: Walter de Gruyter, GmbH; 2019. 575

6. Barnham KJ, Bush A. Biological metals and metal-targeting compounds in major neurodegenerative diseases. Chem Soc Rev. 2014;43(19):67276749.

7. Basu A. Metals in medicine: an overview. Sci Revs Chem Commun 2015;5(2):77-87.

8. Dabroniak JC. Metals in Medicine. 2nd ed. New York: Wiley; 2017.

9. Bjorklund G, Stejskal V, Urbina MA, et al. Metals and Parkinson's disease: mechanisms and biochemical processes. Curr Med Chem. 2017.

10. Hyberg PE. Metals in Medicine-a Cure for Malaria? Sweden: Lund University; 2015. 31 p.

11. Ndagi U, Mhlongo N, Soliman ME. Metal complexes in cancer therapy-an update from drug design perspective. Drug Des Devel Ther 2017;11:599-616.

12. Medici S, Peana M, Nurchi VM, et al. Noble metals in medicine: latest advances. Coord Chem Rev. 2015;284:329-350.

13. Crichton RR. Metals in medicine and metal as drugs. In Biological Inorganic Chemistry: A new introduction to molecular structure and function. 2nd ed. Amsterdam: Elsevier; 2012. 415-432 p.

14. Bradford SS, Cowan JA. From traditional drug design to catalytic metallodrugs: A brief history of the use of metals in medicine. Metallodrugs. 2014;1(1):10-23.

15. Storr T. Ligand Design in Medicinal Inorganic Chemistry. New York: Wiley; 2014.

16. Franz KJ. Clawing back: broadening the notion of metal chelators in medicine. Curr Opin Chem Biol. 2013;17(2):143-149.

17. Sigel A, Freisinger E, Sigel RKO. Interrelations Between Essential Metal Ions and Human Diseases. Dordrecht: Springer-Science; 2013.

18. Virag L, Erdodi F, Gergely P. Bioinorganic chemistry for medical students. Hungary: Medicinal Chemistry; 2016. 104 p.

19. Guo Z, Sadler PJ. Metals in medicine. Angew Chem Int Ed Engl. 1999;38(11):1512-1531.

20. Ferguson LN. Chelates in chemotherapy. Ed Chem. 1981;18:166-168.

21. Aaseth J, Crisponi G, Andersen O. Chelation therapy in the treatment of metal intoxication. Amsterdam: Elsevier; 2016. 390 p.
22. Aaseth J, Skaug MA, Cao Y, et al. Chelation in metal intoxication. Principles and paradigms. J Trace Elem Med Biol. 2015;31:260-266.

23. Walker MB, Edwards K, Farmer PJ. Disulfiram, metals, and melanoma. J Chem Educ. 2009;86(10):1224-1226.

24. Buettner KM, Valentine AM. Bioinorganic chemistry of titanium. Chem Rev. 2012;112(3):1863-1881.

25. Steve T, Jennifer D, Tony D. The Biochemical Periodic Table. 2017.

26. Gaynor D, Griffith DM. The Prevalence of metal-based drugs as therapeutic or diagnostic agents: beyond platinum. Dalton Trans. 2012;41(43):13239-13257.

27. Haas KL, Franz KJ. Application of metal coordination chemistry to explore and manipulate cell biology. Chem Rev. 2009;109(10):49214960 .

28. Kalinkova G. Complexation: Non-Cyclodextrins. In: Swarbrick J, editor. Encyclopedia of Pharmaceutical Technology; 3rd ed. New York: Informa Healthcare; 2007. 697-705 p.

29. Orvig C, Abrams MJ. Medicinal inorganic chemistry. Chem Rev. 1999;99(9):2201-2204.

30. Cronin L. http://www.chem.gla.ac.uk/cronin/files/lectures/MIM/ Metals\%20in\%20Medicine\%20-\%20Full.pdf

31. Ronconi L, Sadler PJ. Using coordination chemistry to design new medicines. Coord Chem Rev. 2007;251(13-14):1633-1648.

32. Alesio E. Bioinorganic Medicinal Chemistry. Weinheim: Wiley-VCH; 2011.

33. Dabrowiak JC. Metals in Medicine. New York: Wiley; 2009.

34. Ronconi L, Fregona D. The midas touch in cancer chemotherapy: from platinum- to gold-dithiocarbamato compleses. Dalton Trans. 2009;48:10670-10680.

35. Barry NPE, Sadler PJ. Exploration of the medical periodic table: towards new targets. Chem Commun (Camb). 2013;49(45):5106-5131.

36. Santini C, Pellei M, Gandin V, et al. Advances in copper complexes as anticancer agents. Chem Rev. 2014;114(1):815-862.

37. Caravan P, Ellison JJ, McMurry TJ, et al. Gadolinium(III) chelates as MRI contrast agents: structure, dynamics and applications. Chem Rev. 1999;99(9):2293-2352.

38. Wilson JJ, Lippard SJ. Synthetic method for the preparation of platinum anticancer complexes. Chem Rev. 2014;114(8):4470-4495.

39. Wheate NJ, Walker S, Craig GE, et al. The status of platinum anticancer drugs in the clinic and in clinical trials. Dalton Trans. 2012;39(35):81138127.

40. Uversky VN, Kretsinger RH, Permyakov EA. Encyclopedia of Metalloproteins. New York: Springer; 2013. 89 p.

41. Iakovidis I, Delimaris I, Iperakis M. Copper and its complexes in medicine: a biochemical approach. Mol Biol Int. 2011; 594529:1-13.

42. Díaz MR, Vivas-Mejia PE. Nanoparticles as drug delivery systems in cancer medicine: emphasis on RNAi-containing nanoliposomes. Pharmaceuticals (Basel). 2013;6(11):1361-1380.

43. Egorova KS, Ananikiv VP. Toxicity of Metal Compounds: Knowledge and Myths. Organometallics, 2017;36(21):4071-4090.

44. Peng Y, Liu YE, Ren XC, et al. A phase I clinical trial of dose esca- lation of lobaplatin in combination with fixed-dose docetaxel for the treatment of human solid tumours that had progressed following chemotherapy. Oncol Lett. 2015;9(1):67-74. 
45. Romero-Canelón I, Sadler PJ. Next-Generation Metal Anticancer Complexes: Multitargeting via Redox Modulation. Inorg Chem. 2013;52(21):12276-12291.

46. Scott LE, Orvig C. Medicinal inorganic chemistry approaches to passivation and removal of aberrant metal ions in disease. Chem Rev 2009;109(10):4885-4910.

47. Caujolle R, Caujolle F, Cousse H. Pharmacological aptitude of organometallics. Lab Pharm. 1979;291:3-7.

48. Kosnett MJ. Chelation for heavy metals (arsenic, lead and mercury) protective or perilous? Clin Pharmacol Ther. 2010;88(3):412-415.

49. Flora SJS. Metal poisoning: threat and management. Al Ameen J Med Sci. 2009;2(2):4-26.

50. Pillay VV. Current views on antidotal therapy in managing cases of poissoning and overdose. $J$ Assoc Physicians India. 2008;56:881-892.

51. Blanusa M, Varnas VM, Piasek M, et al. Chelators as antidotes of metal toxicity: therapeutical and experimental aspects. Curr Med Chem. 2005;12(23):2771-2794.

52. Flanagan RJ, Jones AL. Antidotes: Principles and Clinical Applications. New York: Taylor and Francis; 2001. 352 p.

53. Trowbridge JP. Historical Perspectives on the Development of Chelation Therapies. Texas: Advanced Training Seminar on Heavy Metal Toxicity, Life Center Houston; 1998. 117 p.

54. Jones MM, Pratt TH. Therapeutic chelating agents. J Chem Educ. 1976;53(6):342-347.

55. Jones MM. New Developments in therapeutic chelating agents as antidotes for metal posoning. Crit Rev Toxicol. 1991;21(3):209-233.

56. Mckenzie-Nickson S, Bush AI, Barnham KJ. Bis(thiosemicarbazone) metal complexes as therapeutics for neurodegenerative diseases. Curr Top Med Chem. 2016;16(27):3058-3068.

57. Kamalinia G, Khodagholi F, Atyabi F, et al. Enhanced brain delivery of deferasirox-lactoferrin conjugates for iron chelation therapy in neurodegenerative disorders: in vitro and in vivo studies. Mol Pharm. 2013;10(12):4418-4131.

58. Rimola A, Alí-Torres J, Rodríguez-Rodríguez $\mathrm{C}$, et al. Ab initio design of chelating ligands relevant to alzheimer's disease: influence of metalloaromaticity. J Phys Chem A. 2011;115(45):12659-12666.

59. Rodríguez CR, Sánchez de Groot N, Rimola A, et al. Design, selection, and characterization of thioflavin-based intercalation compounds with metal chelating properties for application in alzheimer's disease. $J \mathrm{Am}$ Chem Soc. 2009;131(4):1436-1451.

60. Storr T, Merkel M, Song-Zhao GX, et al. Synthesis, characterization, and metal coordinating ability of multifunctional carbohydratecontaining compounds for alzheimer's therapy. J Am Chem Soc. 2007;129(23):7453-7463.

61. Muhammad N, Guo Z. Metal-Based anticancer chemotherapeutic agents. Curr Opin Chem Biol. 2014;19:144-153.

62. Alderden RA, Hall MD, Hambley TW. The discovery and development of cisplatin. J Chem Educ. 2006;83(5):729-734.

63. Jia O, Ouyag R, Cao P, et al. Review: recent advances and future development of metal complexes as anticancer agents. J Coord Chem. 2017;70(13):2175-2201.

64. Risoluti R, Materazzi S, Sorrentino F, et al. Update on thalassemia diagnosis: new insights and methods. Talanta. 2018;183:216-222.

65. Risoluti R, Materazzi S, Sorrentino F, et al. Thermogravimetric analysis coupled with chemometrics as a powerful predictive tool for $\beta$ thalassemia screening. Talanta. 2016;159:425-432.
66. Dobbin PS, Hider RC. Iron chelation therapy. Chem Brit. 1990;1:565568 .

67. Harris DC. Quantitative Chemical Analysis. 8th ed. New York: WH Freeman and Co.; 2010. 892 p.

68. Sebestík J, Safarík M, Bour P. Ferric Complexes of 3-hydroxy-4pyridinones characterized by density functional theory and raman and UV-vis spectroscopies. Inorg Chem. 2012;51(8):4473-4481.

69. Sorenson JR. Copper complexes in biochemistry and pharmacology. Chem Brit. 1984;20(12):1110-1113.

70. Crisponi G, Nurchi VM, Fanni D, et al. Copper-related diseases: from chemistry to molecular pathology. Coord Chem Rev. 2010;254(78):876-889

71. Hordyjewska A, Popiolek L, Kocot J. The many "faces" of copper in medicine and treatment. Biometals. 2014;27(4):611-621.

72. Cuillel M. The dual personality of ionic copper in biology. J Incl Phenom Macrocycl Chem. 2009;65(1-2):165-170.

73. Brown OC, Baguña Torres J, Holt KB, et al. Copper complexes with dissymmetrically substituted bis(thiosemicarbazone) ligands as a basis for PET radiopharmaceuticals: control of redox potential and lipophilicity. Dalton Trans. 2017;46(42):14612-14630.

74. Djoko KY, Goytia MM, Donnelly PS, et al. Copper(II)bis(tiosemicarbazonato) complexes as antibacterial agents: insights into their mode of action and potential as therapeutics. Antimicrob Agents Chemother. 2015;59(10):6444-6453.

75. Sirois JJ, Gallegos M, Beckman JS, et al. 35-Redox properties of therapeutic $\mathrm{Cu}$ Bis(thiosemicarbazone) complexes in a biomimetic environment. Free Rad Biol Med. 2016;100:S30.

76. Herrador MA, Jiménez AM, Asuero AG. Spectrophotometric determination of zinc in potable waters and insulin with methylglyoxal bis(4-phenyl-3-thiosemicarbazone). Analyst. 1987;112(9):1237-1246.

77. Asuero AG, Gonzalez-Balairon M. Analytical applications of biacetyl bis(4-phenyl-3-thiosemicarbazone) and bipiridylglyoxal bis(4-phenyl-3thiosemicarbazone). Microchem J. 1980;25(1):14-45.

78. Crisponi G, Nurchi VM, Bertolasi V, et al. Chelating agents for human diseases related to aluminium. Coord Chem Rev. 2012;256(1-2):89-104.

79. Sanz-Medel A, Cabezuelo ABS, Milacic R, et al. The chemical speciation of aluminium serum. Coord Chem Rev. 2002;228(2):373-383.

80. Martell AE, Hancock RD, Smith RM, et al. Coordination of Al(III) in the environment and in biological systems. Coord Chem Rev. 1996;149:311328.

81. Wills MR, Savory J. Aluminum and chronic renal failure: sources, absorption, transport, and toxicity. Crit Rev Clin Lab Sci. 1989;27(1):59107.

82. Garbutcheon-Singh KB, Harper BWJ, Myers S, et al. Combination studies of platinum(II)-based metallointercalators with buthionine-s, $\mathrm{r}$ sulfoximine, 3-bromopyrivate, cisplatin or carboplatin. Metallomics. 2014;6(1):126-131.

83. Klein AV, Hambley TW. Platinum-based anticancer agents. In: Storr T, editor. Ligand Design in Medicinal Chemistry, New York: Wiley; 2014 9-46 p.

84. Mügge C, Liu R, Görls H, et al. Novel platinum(II) compounds with O,S bidentate ligands: synthesis, characterization, antiproliferative properties and biomolecular interactions. Dalton Trans. 2014;43(8):3072-3086.

85. Butler JS, Sadler PJ. Targeted delivery of platinum-based anticancer compounds. Curr Opin Chem Biol. 2013;17(2):175-188.

86. Klein AV, Hambley TW. Platinum drug distribution in cancer cells and 
tumors. Chem Rev. 2009;109(10):4911-4920.

87. Wong E, Giandomenico CM. Current status of platinum-based antitumor drugs. Chem Rev. 1999;99(9):2451-2461.

88. Zipp AP, Zipp SG. Pt $\left(\mathrm{NH}_{3}\right)_{2} \mathrm{Cl}_{2}$ and cancer: An old compound with a new use. J Chem Educ. 1977;54(12):739-741.

89. Bertrand B, Casini A. A Golden Future in medicinal inorganic chemistry: the promise of anticancer gold organometallic compounds. Dalton Trans. 2014;43(11):4209-4219.

90. Shaw CF. Gold-based therapeutic agents. Chem Rev. 1999;99(9):25892600 .

91. Mrozek-Wilczkiewicz A, Serda M, Musiol R, et al. Iron chelators in photodynamic therapy revisited: synergistic effect by novel highly active thiosemicarbazones. ACS Med Chem Lett. 2014;5(4):336-339.

92. Ma Y, Zhou T, Kong X, et al. Chelating agents for the treatment of systemic iron overload. Curr Med Chem. 2012;19(17):2816-2827.

93. Zhout T, Ma Y, Kong X, et al. Design of iron chelators with therapeutic applications. Dalton Trans. 2012;41(21):6371-6389.

94. Zhou T, Winkelmann G, Dai ZY, et al. Design of clinically useful macromolecular iron chelators. J Pharm Pharmacol. 2011;63(7):893903.

95. Crisponi G, Remelli M. Iron chelating agents for the treatment of iron overload. Coord Chem Rev. 2008;252(10-11):1225-1240.

96. Zhou T, Long XL, Liu ZD, et al. Synthesis and iron(III)-chelating properties of novel 3-hydroxypyridin-4-one hexadentate ligandcontaining copolymers. Biomacromolecules. 2008;9(5):1372-1380.

97. Evans RW, Rafique R, Zarea A, et al. Nature of non-transferrin bound iron: studies on iron citrate complexes and thalassemic sera. J Biol Inorg Chem. 2008;53(1):57-74.

98. Bernhardt PV. Coordination Chemistry and Biology of Chelators for the Treatment of Iron Overload Disorders. Dalton Trans. 2007;14(30):3214 3220 .

99. Kalinowski DS, Richardson DR. Future of toxicology-iron chelators and differing modes of action and toxicity: the changing face of iron chelation therapy. Chem Res Toxicol. 2007;20(5):715-720.

100. Merkofer M, Kissner R, Hider RC, et al. Fenton chemistry and iron chelation under physiologically relevant conditions: electrochemistry and kinetics. Chem Res Toxicol. 2004;19(10):1263-1269.

101. Faa G, Crisponi G. Iron chelating agents in clinical practice. Coord Chem Rev. 1999;184(1):291-310.

102. Senozan NM, Christiano MP. Iron as nutrient and poison. J Chem Educ. 1997;74(9):1060-1063.

103. Spingarn NE, Satorelli AC. Synthesis and evaluation of the thiosemicarbazone, dithiocarbazonate, and 2- pyrazinylhydrazone of pyrazinecarboxaldehyde as agents for the treatment of iron overload. $J$ Med Chem. 1979;22(11):1314-1316.

104. Saltman S. The role of chelation in iron metabolism. J Chem Educ 1965;42(12):682-687.

105. Crichton RR, Florence A, Ward RJ. Aluminium and iron in the brain. Prospects for chelation. Coord Chem Rev. 2002;228(2):365-371.

106. Santos MA. Hydroxypyridone complexes with aluminium. In vitro/vivo studies and perspectives. Coord Chem Rev. 2002;228(2):187-203.

107. Fasman GD. Aluminium and alzheimer's disease: model studies. Coord Chem Rev. 1996;149:125-165.
108. Kheirolomoom A, Mahakian LM, Lai CY, et al. Copper-doxorubicin as a nanoparticle cargo retains efficacy with minimal toxicity. Mol Pharm. 2010;7(6):1948-1958

109. Marzano C, Pellel M, Tisato F, et al. Copper complexes as anticancer agents. Anticancer Agents Med Chem. 2009;9(2):185-211.

110. Zhang L, Lichtmannegger J, Summer KH, et al. Tracing copperthiomolybdate complexes in a prospective treatment for Wilson's disease. Biochem. 2009;48(5): 891-897.

111. Yang CT, Chuang KH. Gd(III) Chelates for MRI contrast aents: from high relaxivity to "smart", from blood probe to blood-brain barrier permeable. Med Chem Commun. 2012;3:552-565.

112. Hermann P, Kotek J, Kubicek V, et al. Gadolinium(III) complexes as MRI contrast agents: ligand design and properties of the complexes. Dalton Trans. 2008;23:3027-3047.

113. Elemento E. New Gadolinium Contrast Agent for MRI. UK: Durham University; 2008. 250 p

114. Fang X, Fernando Q. Stereoisomeric selectivity of 2,3-dimercaptosuccinic acids in chelation therapy for lead poisoning. Chem Res Toxicol. 1995;8(4):525-536.

115. George GN, Prince RC, Gailer J, et al. Mercury binding to the chelation therapy agents DMSA and DMPS and the rational design of custom chelators for mercury. Chem Res Toxicol. 2004;17(8):999-1006.

116. Fang X, Hua F, Fernando QF. Comparison of rac- and meso-2,3dimercaptosuccinic acids for chelation of mercury and cadmium using chemical speciation models. Chem Res Toxicol. 1996;9(1):284-290.

117. Cao Y, Skaug MA, Andersen O, et al. Chelation therapy in intoxications with mercury, lead and copper. J Trace Elem Med Biol. 2015;31:188192.

118. Labianca DA. A classic case of thallium poisoning and scientific serendipity. J Chem Educ. 1990;67(12):1019-1021.

119. Hahn EM, Casini A, Kühn FE. Re(VII) and Tc(VII) trioxocomplexes stabilized by tridentate ligands and their potential use as radiopharmaceuticals. Coord Chem Rev. 2014;276:97-111.

120. Yamgar RS, Nivid Y, Nalawade S, et al. Novel Zin(II) Complexes of heterocyclic ligands as antimicrobial agens: synthesis, characterization, and antimicrobial studies. Bioinorg Chem Appl. 2014;2014:276598.

121. Wilson JJ, Ferrier M, Radchenko V, et al. Evaluation of nitrogenrich macrocyclic ligands for the chelation of therapeutic bismuth radioisotopes. $\mathrm{Nucl}$ Med Biol. 2015;42(5):428-438.

122. Ge R, Sun H. Bioinorganic chemistry of bismuth and antimony: target sites of metallodrugs. Acc Chem Res. 2007;40(4):267-274.

123. Odularu AT. Cobalt compounds as multifaceted chemotherapeutic agent: an overview. Int J Progress Sci Technol. 2016;2(2):71-73.

124. Heffern MC, Yamamoto N, Holbrook RJ, et al. Cobalt derivatives as promising therapeutic agents. Curr Opin Chem Bio. 2013;17(2):189196.

125. Ouyang L, Randaccio L, Rulis P, et al. Electronic structure and bonding in vitamin B12, cyanocobalamin. J Mol Struct. 2003;622(3):221-227.

126. Gorden AEV, Xu J, Raymond KN. Rational design of sequestering agents for plutonium and other actinides. Chem Rev. 2003;103(11):4207-4282.

127. Xu J, Durbin PW, Kullgren B, et al. Synthesis and initial evaluation for in vivo chelation of $\mathrm{pu}(\mathrm{IV})$ of a mixed octadentate spermine-based ligand containing 4-carbamoyl-3 hydroxy-1-methyl-2(1H)-pyridinone and 6-carbamoyl-1-hydroxy-2(1H)-pyridinone. $J$ Med Chem. 2002;45(18):3963-3971. 
128. Caballero AB, Rodríguez-Dieguez A, Salas JM, et al. Lanthanide complexes containing 5-methyl-1,e,4-triazole[1,5-a]pyrimidin-7(4H)one and thir therapeutic potential to fight leishmaniasis and chagas disease. J Inorg Biochem. 2014;138:39-46.

129. Mawani Y, Cawthray JF, Chang S, et al. In vitro studies of lanthanide complexes for the treatment of osteoporosis. Dalton Trans. 2013;42(17):5999-6011.

130. Barta CA, Sachs-Barrable K, Jia J, et al. Lanthanide containing compounds for therapeutic care in bone resorption disorders. Dalton Trans. 2007;43:5019-5030.

131. Fricker SP. The therapeutic application of lanthanides. Chem Soc Rev. 2006;35(6):524-533.

132. Liu S, Edwards DS. Bifunctional chelators for therapeutic lanthanide radiopharmaceuticals. Bioconjugate Chem. 2001;12(1):7-34.

133. Kepp KP. Bioinorganic chemistry of Alzheimer's disease. Chem Rev. 2012;112(10):5193-5239.

134. Mathew RO, Schulman-Marcus J, Nichols EL, et al. Chelation therapy as a cardiovascular therapeutic strategy: the rationale and the data in review. Cardiovasc Drugs Ther. 2017;31(5-6):619-625.

135. Sultan S, Murarka S, Jahangir A, et al. Chelation therapy in cardiovascular disease: an update. Expert Rev Clin Pharmacol. 2017;10(8):843-854.

136. Ibad A, Khalid R, Thompson PD. Chelation therapy in the treatment of cardiovascular diseases. J Clin Lipodol. 2016;10(1):58-62.

137. Kustov AV, Berezin BD, Trostin VN. The complexon-renal stone interaction: solubility and electronic microscopy studies. J Phys Chem. 2009;113(28):9547-9550.

138. Hart JR. EDTA-Type chelating agents in everyday consumer products: some food, cleaning, and photographic applications. J Chem Educ. 1985;62(1):75-76.

139. Hart JR. EDTA-type chelating agents in everyday consumer products: some medicinal and personal care products. J Chem Educ. 1984;61(12):1060-1061.

140. Tian F, Decker EA, Goddard JM. Controlling lipid oxidation via a biomimetic iron chelating active packaging material. J Agric Food Chem. 2013;61(50):12397-12404.

141. Omur-Ozbek P, Dietrich AM, Duncan SE, et al. Role of lipid oxidation, chelating agents, and antioxidants in metallic flavor development in the oral cavity. J Agric Food Chem. 2012;60(9):2274-2280.

142. Tian F, Decker EA, Goddard JM. Development of an iron chelating polyethylene film for active packaging applications. J Agric Food Chem. 2012;60(8):2046-2052.

143. Liu ZQ. Chemical methods to evaluate antioxidant ability. Chem Rev. 2010;110(19):5675-5691.

144. Mewis RE, Archibald SJ. Biomedical aplications of macrocyclic ligand complexes. Coord Chem Rev. 2010;254(15-16):1686-1712.

145. Zhou CH, Zhang YY, Yan CY, et al. Recent Researches in metal supramolecular complexes as anticancer agents. Anticancer Agents Med Chem. 2010;10(5):371-395.
146. Smith DK. A Supramolecular approach to medicinal chemistry: medicine beyond the molecule. J Chem Educ. 2005;82(3):393-400.

147. Wang B, Galliford CV, Low PS. Guiding principles in the design of ligand-targeted nanomedicines. Nanomedicine. 2014;9(2):313-330.

148. Storr T, Thompsona KH, Orvig C. Design of targeting ligands in medicinal inorganic chemistry. Chem Soc Rev. 2006;35(6):534-544.

149. Chiang L, Jones MR, Ferreira CL, et al. Multifunctional ligands in medicinal inorganic chemistry: current trends and future directions. Curr Top Med Chem. 2012;12(3):122-144

150. Price EW, Orvig C. Matching chelators to radiometals for radiopharmaceuticals. Chem Soc Rev. 2014;43(1):260-290.

151. Gasser G, Metzler-Nolte N. The potential of organometallic complexes in medicinal chemistry. Curr Opin Chem Biol. 2012;16(1-2):84-91.

152. Gasser G, Ott I, Melzler-Notte N. Organometallics anticancer compounds. J Med Chem. 2011;54(1):3-25.

153. Frezza M, Hindo S, Chen D, et al. Novel metals and metal complexes as platforms for cancer therapy. Curr Pharm Des. 2010;16(6):1813-1825.

154. Cragg GM, Grothaus PG, Newman DJ. Impact of natural products on developing new anti-cancer agents. Chem Rev. 2009;109(7):3012-3043.

155. Bruijnincx PCA, Sadler PJ. New trends for metal complexes with anticancer activity. Curr Opin Chem Biol. 2008;12(2):197-206.

156. Goebel T, Ulmer D, Projahn H, et al. In search of novel agents for therapy of tropical diseases and human immunodeficiency virus. $J \mathrm{Med}$ Chem. 2008;51(2):238-250.

157. Heeg MJ, Jurisson SS. The role of inorganic chemistry in the development of radiometal agents for cancer therapy. Acc Chem Res. 1999;32(12):1053-1060.

158. Sharma V, Piwnica-Worms D. Metal complexes for therapy and diagnosis of drug resistance. Chem Rev. 1999;99(9):2545-2560.

159. Köpf-Maier P, Köpf H. Non- platinum- group metal antitumor agents: history, current status, and perspectives. Chem Rev. 1987;87(5):11371152.

160. Roundhill DM. Novel strategies for the removal of toxic metals from soils and waters. J Chem Educ. 2004;81(2):275-282.

161. Nowack B, VanBriesen JM. Chelating agents in the environment. In: Nowack B, vanBriesen JM, Editors. Biochemistry of Chelating Agents. Washington DC: ACS; 2005.

162. Francis MD, Centner RL. The development of diphosphonates as significant health care products. J Chem Educ. 1978;55(12):760-766.

163. Bromberg L, Schreuder-Gibson H, Creasy WR, et al. Degradation of chemical warfare agents by reactive polymers. Ind Eng Chem Res. 2009;48(3):1650-1659.

164. Farrell N. Metal complexes as drugs and chemotherapeutic agents. In: Ward MD, editor. Comprehensive Coordination Chemistry II. From biology to nanotechnology. Applications of Coordination Chemistry. Amsterdam: Elsevier; 2003. 809-840 p. 